\title{
Identification and adhesion profile of Lactobacillus spp. strains isolated from poultry
}

\author{
Ticiana Silva Rocha, Ana Angelita Sampaio Baptista, Tais Cremasco Donato, \\ Elisane Lenita Milbradt, Adriano Sakai Okamoto, Raphael Lucio Andreatti Filho
}

Laboratório de Ornitopatologia, Faculdade de Medicina Veterinária e Zootecnia, Universidade Estadual

Paulista, Botucatu, SP, Brazil.

Submitted: September 18, 2012; Approved: March 14, 2014.

\begin{abstract}
In the aviculture industry, the use of Lactobacillus spp. as a probiotic has been shown to be frequent and satisfactory, both in improving bird production indexes and in protecting intestine against colonization by pathogenic bacteria. Adhesion is an important characteristic in selecting Lactobacillus probiotic strains since it impedes its immediate elimination to enable its beneficial action in the host. This study aimed to isolate, identify and characterize the in vitro and in vivo adhesion of Lactobacillus strains isolated from birds. The Lactobacillus spp. was identified by PCR and sequencing and the strains and its adhesion evaluated in vitro via BMM cell matrix and in vivo by inoculation in one-day-old birds. Duodenum, jejunum, ileum and cecum were collected one, four, 12 and $24 \mathrm{~h}$ after inoculation. The findings demonstrate greater adhesion of strains in the cecum and an important correlation between in vitro and in vivo results. It was concluded that BMM utilization represents an important technique for triage of Lactobacillus for subsequent in vivo evaluation, which was shown to be efficient in identifying bacterial adhesion to the enteric tract.
\end{abstract}

Key words: Lactobacillus, identification, intestinal adhesion.

\section{Introduction}

Probiotics are defined as microorganisms that, when administered in suitable quantities, confer health benefits to the host (FAO/WHO, 2002). In the aviculture industry, supplementation with probiotics, especially Lactobacillus, has been shown efficient in augmenting weight gain, improving the alimentary conversion rate, and diminishing mortality in birds of production (Huang et al., 2004). Due to the growing interest in the utilization of these microorganisms as probiotics, their correct identification becomes necessary (Moreira et al., 2005).

Given that many Lactobacillus species have similar nutritional and growth requirements, it is often difficult to apply classical microbiology methods to identify them with precision. Several research studies have focused on the application of molecular biology techniques to achieve rapid detection and differentiation of this specie. The use of primers and probes that rDNA sequences coding for the $16 \mathrm{~S}$ and 23S rRNA has been validated as a means of identification. (Dubernet et al., 2002).
The adhesion of Lactobacillus to the epithelium was defined as a characteristic of interest for selection of probiotic strains, since it represents the first step in the formation of a barrier to prevent colonization by undesirable microorganisms due to competition for nutrients and adherence sites, in addition to preventing its immediate elimination by intestinal peristalsis (Collado et al., 2005); but despite this, information on its adhesion to the intestinal epithelium of poultry remains scarce (Morelli, 2002).

The use of in vitro models, including epithelial cells, mucosal components and extracellular matrix components such as laminin, fibronectin, collagen and proteoglycans, found in the commercial product Basement Membrane Matrix - BMM (BD - Becton Dickinson, USA), could be very useful, once it demonstrate the adhesion capacity of Lactobacillus, both individually and collectively (Horie et al., 2002; Vellez et al., 2007).

Although none of the previously cited methods in $v i$ tro reflect the complex interactions that occur in the mucosa of the gastrointestinal tract in vivo, they represent a

Send correspondence to T.S. Rocha. Ornitopatology Laboratory, College of Veterinary Medicine and Animal Science, São Paulo State University, 18618-970 Botucatu, SP, Brazil. E-mail: ticirocha@yahoo.com.br. 
rapid method for characterizing and selecting strains of Lactobacillus, and according to Muñoz-Provencio et al. (2009), in most cases there is a high correlation between results found in vitro and those obtained from in vivo tests.

The staining of Lactobacillus by the fluorescence technique is a highly accurate and reproducible technique for tracking and quantifying bacterial cells, especially via in vivo models (Bianchi et al., 2004), and one option is to utilize carboxyfluorescein succinimidyl amino ester (CFDA SE), which is colourless and nonfluorescent until its acetate group is cleaved by intracellularesterase to yield highly fluorescent, amine-reactive carboxyfluorescein succinimidyl ester (Bouzaine et al., 2005) that allows easily distinguish form from the native bacterial population of the intestine, without having their adhesion, survival capacity or membrane properties altered by the staining agent (Fuller et al., 2000).

The present work aimed to identify, by polymerase chain reaction (PCR), strains of Lactobacillus spp. isolated from chicken, to evaluate their adhesion capacity in vitro and in vivo in one-day-old birds and posterior sequencing.

\section{Material and Methods}

\section{Isolation of Lactobacillus spp.strains}

The isolation and genus identification of Lactobacillus strains were done as described before by Barros et al. (2009) using crop and cecum of thirty Cobb breeders, aged 65 weeks collected aseptically.

\section{Confirmation of Lactobacillus spp. identification by Polymerase Chain Reaction (PCR) technique}

The bacterial strains that presented characteristics compatible with the Lactobacillus genus were submitted to confirmation by means of PCR. The following strains were utilized as positive reaction controls: Lactobacillus fermentum CCT0559-ATCC9338, L. reuteri CCT3433 ATCC23272, L. acidophilus CCT3258-ATCC4356, L. casei ssp. casei CCT 1465- ATCC 393, L. delbrueckii ssp. lactis CCT7520-ATCC7830 and L. helveticus - CCT 3747 ATCC 15009.

For this purpose, DNA was extracted from the strains utilizing the kit QIAamp DNA blood Mini Kit (Qiagen, USA) according to the manufacturer's instructions. The following primers: Forw R16-1 (5'-CTT GTA CAC ACC GCC CGT CA- 3') and Rev LbLMA1- (5'-CTC AAA ACT AAA CAA AGT TTC -3'), the reaction and cycle employed were according to previously described by Dubernet et al. (2002) in order to amplify a product of approximately $250 \mathrm{pb}$.

\section{In vitro adhesion in cell matrix type BMM}

Each Lactobacillus strain was submitted to an adhesion test, as described by Bouzaine et al. (2005) utilizing the cell matrix type Basement Membrane Matrix (BMM).
To prepare the slides with BMM matrix, the same was diluted (1:20) in PBS; and $35 \mathrm{uL}$ was deposited on Falcon ${ }^{\circledR}$ (BD) slide at $4{ }^{\circ} \mathrm{C}$. The slides were maintained in repose at $37{ }^{\circ} \mathrm{C}$ for two $\mathrm{h}$ and then incubated with phosphate buffer solution (PBS) with the addition of $2 \%$ bovine serum albumin (BSA) for one hour at room temperature.

The preparation of the Lactobacillus strains consisted of incubating the bacterial cells in MRS broth for $24 \mathrm{~h}$ at $37{ }^{\circ} \mathrm{C}$, centrifuging $(13,000 \times \mathrm{g}$ for $3 \mathrm{~min})$ and washing twice with one $\mathrm{mL}$ of PBS. Subsequently, $200 \mu \mathrm{L}$ of this solution at the concentration of $10^{7} \mathrm{UFC} \mathrm{mL}^{-1}$ was deposited on slides previously prepared with BMM and incubated for two $h$ at room temperature. After incubation, the slides were washed three times with PBS, submitted to Gram staining and read in an optical microscope.

Three repetitions were performed for each strain tested, with eight fields being counted in each one in a rectangular area of $1.7 \times 1.0 \mathrm{~cm}$. The area for counting in each microscopic field was $3.8 \times 10^{-2} \mathrm{~mm}^{2}$, utilizing a $100 \mathrm{x}$ objective. The counts were performed by double-blind study. A strain of Escherichia coli isolated from chicken and a $\mathrm{Ba}$ cillus subtilis 168 were utilized as positive and negative control, respectively.

\section{In vivo adhesion of Lactobacillus spp. in intestinal epithelium of birds}

Culturing and bacterial staining with carboxyfluorescein succinimidyl amino ester (CFDA SE).

Based on the in vitro adhesion test, the five Lactobacillus spp. strains that had obtained the best adhesion results in BMM were selected for the in vivo test.

The strains of Lactobacillus spp. and Bacillus subtilis were cultured in MRS broth and Luria broth (LB), respectively, until they reached a stationary phase (16 h). Subsequently, they were centrifuged at $9300 \mathrm{x} g$ for five minutes, washed twice in PBS and resuspended in PBS ( $\mathrm{pH} 7.5)$ to obtain a concentration of $10^{10} \mathrm{cfu} \mathrm{mL}^{-1}$. The strains were stained with Vybrant CFDA SE Tracer (Invitrogen) according to the manufacturer's recommendations using $50 \mu \mathrm{mol} \mathrm{L}{ }^{-1}$ of CFDA SE solution at $37^{\circ} \mathrm{C}$ for $30 \mathrm{~min}$. The stained cells were then centrifuged, washed twice in PBS and re-suspended to its initial volume in the proper culture broth (MRS or LB) and incubated again at $37^{\circ} \mathrm{C}$ for $30 \mathrm{~min}$. The stained cultures were protected from light and maintained at $4{ }^{\circ} \mathrm{C}$ until inoculation in birds.

\section{Experimental design}

168 one-day-old Ross lineage breeders were utilized, divided into seven groups composed of 24 animals each. In each group the following different bacterial strains stained with CFDA SE were inoculated: negative control group (Bacillus subtillis), positive control group (L. reuteri CCT3433 - ATCC23272) and five other groups (strains 311, 262, 258, 231 and 206). 
Prior to the in vivo assay a pilot test was performed with a group in which the birds did not receive any type of stained microorganism, to certify that only the inoculated strains would be detected by fluorescence.

The inoculum was administered orally, with the aid of a gavage needle, directly into the crop. Alimentation was suspended $12 \mathrm{~h}$ before this procedure. The collection moments were at one, four, 12 and $24 \mathrm{~h}$ after treatment.

\section{Preparation of intestine fragments from birds}

At each of the four moments after bacterial inoculation, six birds per group were humanely euthanized by cervical dislocation, and cranial one-centimeter portions of duodenum, jejunum, ileum and cecum were collected. All visible residues were carefully removed to avoid damaging the intestinal mucosa. The collected fragments were immediately frozen via submersion in liquid nitrogen and stored at $-80{ }^{\circ} \mathrm{C}$ until the histological preparation. The fragments were collected with the aid of a micro-cryostat and prepared on slides containing five histological cuts (8 to $10 \mu \mathrm{m}$ each). The slides were protected from light and stored at -20 ${ }^{\circ} \mathrm{C}$ until analysis.

To quantify the attached Lactobacillus spp. and $B a-$ cillus subtilis, two random microscopic fields were observed in each cut, totaling ten counting fields per slide/fragment. The counting area in each microscopic field was $3.8 \times 10^{-2} \mathrm{~mm}^{2}$. The reading was performed in a fluorescence microscope and the results were expressed as the median number of stained bacteria per histological cut.

\section{Sequencing}

The PCR products of the five best adhesive strains at in vitro test were cloned at $\mathrm{pGem}$ vector (Promega), accordingly to the manufacture's recommendation, utilizing vector' primers $F w$-M13 5'-CACGACGTTGTAAAACGAC-3' e rev-M13 5'-GGATAACAATTTCACACAGG-3'. The sequences of the $16 \mathrm{~S} / 23 \mathrm{~S}$ ribosomal RNA intergenic spacer region of phylogenetically related species: L. acidophilus (U32971), L. amylovorus (AF182732), L. casei subsp. casei (Z75478), L. crispatus (AF074857), L. delbrueckii subsp. bulgaricus (Z75475), L. fermentum (AF080099), L. gasseri (AF074859), L. hamsteri (AF113601), L. helveticus (Z75482), L. jensenii (AB035486), L. johnsonii (AF074860), L. plantarum (U97139), L. reuteri (AF080100), L. rhamnosus (AF121201), L. sakei (U97137), L. salivarius (AF113600), L. vaginalis (AF182731) were retrieved from GenBank (www.ncbi.nlm.nih.gov) and used to perform multiple alignments with the our strains sequences using Clustal W (Tamura et al., 2011).

\section{Statistical analysis}

The results obtained in vitro were transformed to $\log _{10}$ form; the mean and standard deviation and subse- quently the confidence interval were calculated to determine the upper and lower limits, which were compared with the mean of the positive control. A 5\% significance level was adopted (Sampaio, 2002).

For the in vivo counts we used a non-parametric analysis of variance (Dunn test), utilizing the median values of bacterial counts, with a two-factorial scheme (Zar, 2009). A $5 \%$ significance level was adopted in all tests and the datas were submitted to the software SIGMASAT (Surhone et al., 2010).

\section{Results}

\section{Identification of Lactobacillus spp.}

Of the strains analyzed, 123 were compatible with the genus Lactobacillus in the aforementioned tests and were then submitted to PCR. Of this total, only 73 strains were positive (see Figure 1).

\section{In vitro adhesion in cellular matrix type BMM}

After identification of the genus Lactobacillus by PCR, each of the strains (73) was submitted to in vitro adhesion test in BMM. Table 1 displays the counts of the microorganisms adhering to the BMM matrix.

The visualization of the Escherichia coli strain utilized as a positive control and the Bacillus subtilis 168 strain employed as a negative control is represented in Figure $2, \mathrm{~A}$ and $\mathrm{B}$.

In the present study, it was possible to determine that the strains of Lactobacillus spp. isolated from the bird intestines are capable of adhering to BMM (Figure $3 \mathrm{~A}$ and B). We can observe greater adhesion capacity in strains 206, 231, 258, 262 and 311 with mean counts of bacteria adhering in BMM closer to the positive control (Table 1). In this manner, these five strains were selected for the in vivo adhesion test.

\section{Adhesion in vivo of Lactobacillus spp. strains}

The median counts of adherent cells in the in vivo test of Bacillus subtillis (negative control), Lactobacillus reuteri (positive control) and of the test of strains 206, 231, 258, 262 and 311 are shown in Table 2.

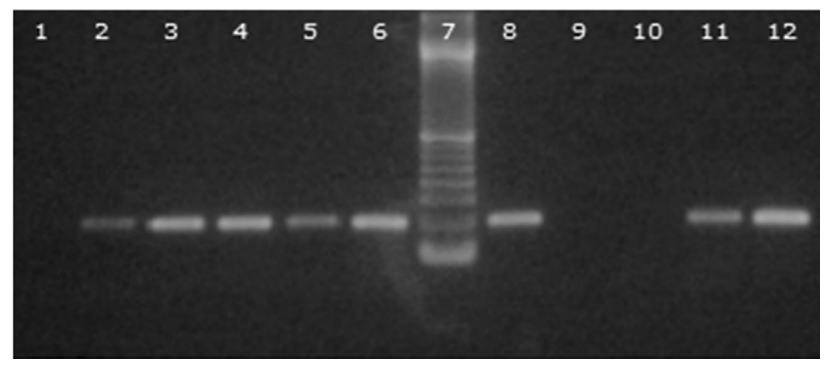

Figure 1 - Agarose gel 1.5\%. 1-Negative control; 2- Lactobacillus acidophilus CCT3258; 3-L. casei CCT 1465; 4-L. delbrueckii CCT 7520; 5-L. fermentum CCT 0559; 6-L. helveticus CCT 3747; 8-L. reuteri CCT3433; 9 and 10-Samples negative for Lactobacillus spp.; 11 and 12-Samples positive for Lactobacillus spp.; 7-Molecular weight 100 bp. 
Table 1 - Result of the in vitro adhesion test represented by mean number of bacterial Lactobacillus spp cells adhering to BMM matrix.

\begin{tabular}{|c|c|c|c|}
\hline Identification of strains & Mean & Identification of strains & Mean \\
\hline E. coli (positive control) & 206.12 & 250 & 2.62 \\
\hline B. subtilis (negative control) & 7.08 & 251 & 6.79 \\
\hline 203 & 6.00 & 252 & 2.33 \\
\hline 204 & 2.70 & 253 & 2.08 \\
\hline 206 & 111.70 & 254 & 2.00 \\
\hline 208 & 71.70 & 255 & 3.33 \\
\hline 210 & 3.37 & 256 & 6.16 \\
\hline 211 & 6.87 & 257 & 4.25 \\
\hline 212 & 56.29 & 258 & 106.25 \\
\hline 214 & 19.5 & 259 & 3.83 \\
\hline 215 & 65.66 & 260 & 3.33 \\
\hline 216 & 42.65 & 261 & 18.54 \\
\hline 217 & 13.16 & 262 & 231.41 \\
\hline 218 & 40.29 & 263 & 5.87 \\
\hline 219 & 49.16 & 264 & 2.75 \\
\hline 220 & 29.16 & 265 & 3.33 \\
\hline 221 & 17.70 & 266 & 3.66 \\
\hline 222 & 6.75 & 267 & 5.70 \\
\hline 224 & 8.12 & 268 & 2.79 \\
\hline 226 & 5.83 & 271 & 7.25 \\
\hline 227 & 19.91 & 273 & 1.12 \\
\hline 230 & 13.66 & 305 & 2.04 \\
\hline 231 & 254.87 & 306 & 1.08 \\
\hline 234 & 7.08 & 307 & 2.04 \\
\hline 237 & 10.04 & 308 & 16.16 \\
\hline 238 & 21.00 & 309 & 1.83 \\
\hline 239 & 26.45 & 310 & 23.70 \\
\hline 240 & 12.79 & 311 & 109.54 \\
\hline 241 & 15.25 & 312 & 9.91 \\
\hline 242 & 11.12 & 318 & 2.29 \\
\hline 243 & 6.45 & 319 & 2.08 \\
\hline 244 & 18.29 & 320 & 7.04 \\
\hline 245 & 11.83 & 321 & 9.95 \\
\hline 246 & 2.20 & 322 & 12.95 \\
\hline 247 & 1.66 & 323 & 4.66 \\
\hline 248 & 5.5 & 324 & 5.16 \\
\hline 249 & 2.91 & 325 & 1.54 \\
\hline
\end{tabular}




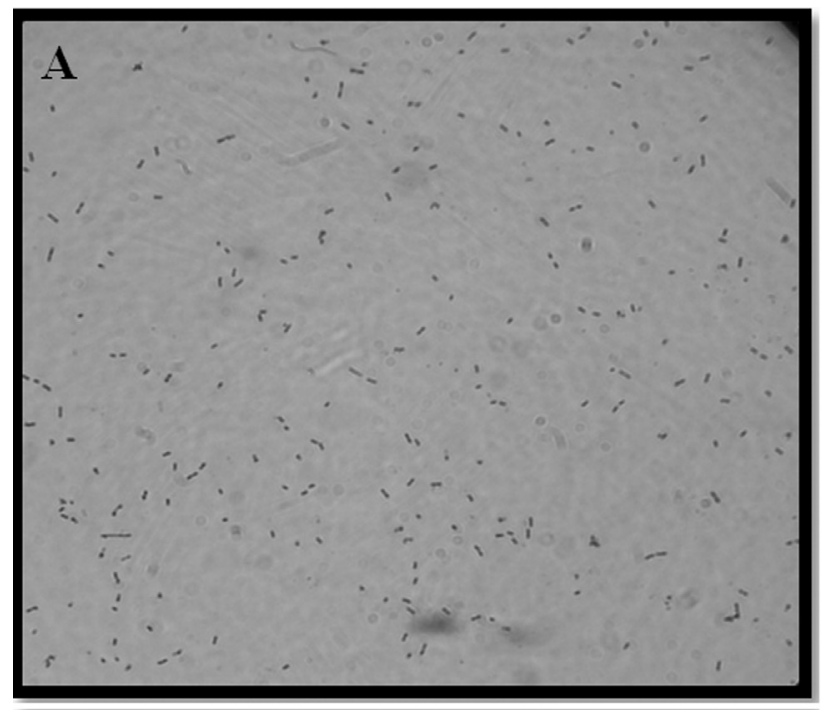

B

Figure 2 - Optical microscopic image (100x) of Escherichia coli (A) and Bacillus subtillis (B), stained by Gram, demonstrating high and low adherence of strains in BMM matrix by in vitro adhesion tests, respectively.

As expected, in the group in which the birds did not receive stained microorganisms, no type of fluorescence or staining was found. The visualization of the Lactobacillus $s p p$. strains stained in different intestinal segments is represented in Figure 4.

The greatest bacterial count was found in strain 262 in the cecum, four hours after inoculation. However, a decrease in the counts was observed at the moments 12 and 24 $\mathrm{h}$ after inoculation.

In the four different intestinal segments during the time of the experiment, it was observed that all strains presented a greater quantity of Lactobacillus adhering at $1 \mathrm{~h}$ and $4 \mathrm{~h}$ than at $24 \mathrm{~h}$, but this was not found in the cecum fragments of the treatments with strains 231 and 206.

The positive control presented reduced counts in all segments as time elapsed, demonstrating low adherence to intestinal epithelium. In general, the cecum was the seg-
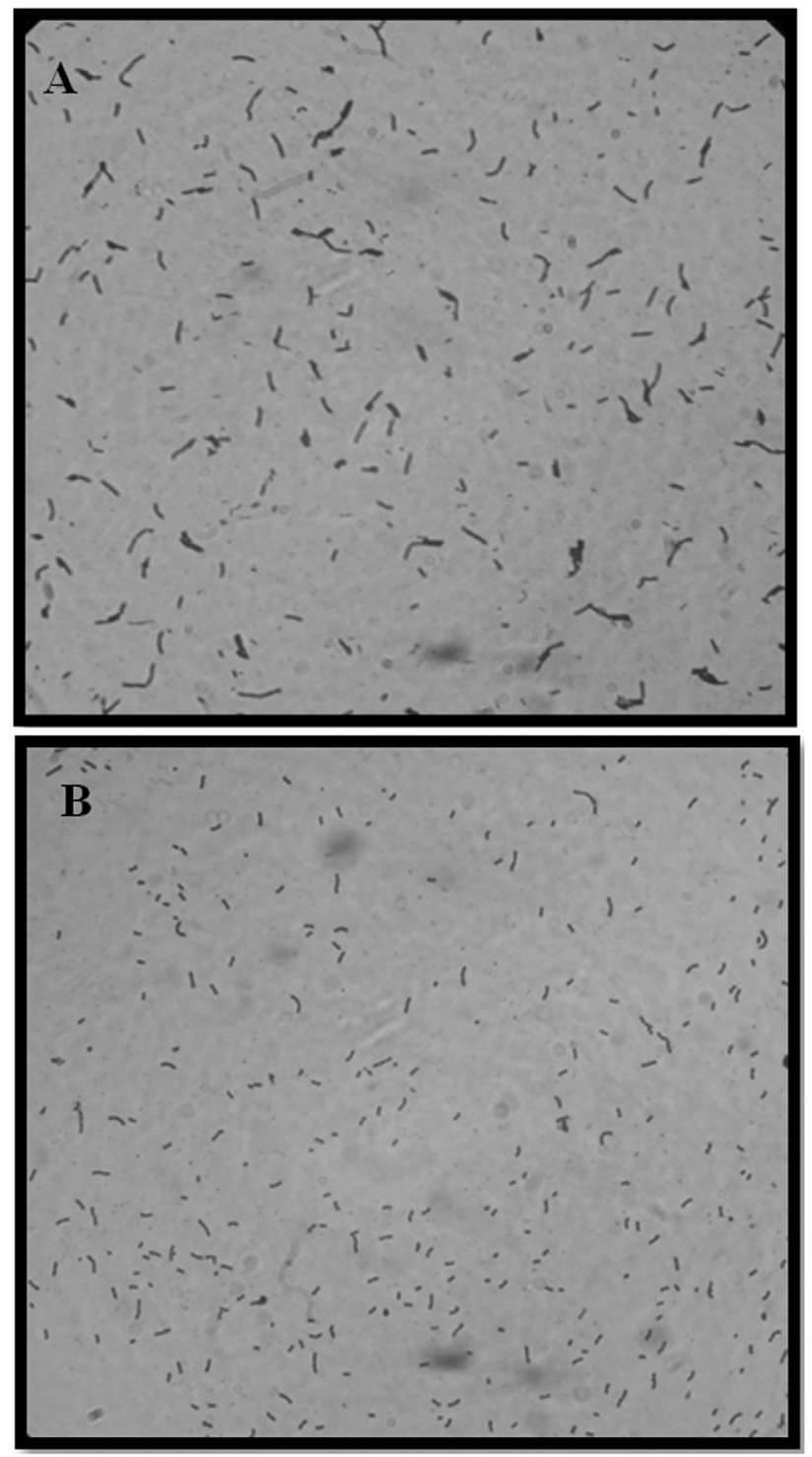

Figure 3 - Optical microscopic image (100x) of Strains 231 (A) and 262 (B), stained by Gram, demonstrating high adherence rate in BMM matrix in in vitro adhesion tests.

ment that demonstrated the greatest quantity of adhering Lactobacillus, with the exception of strain 258. But this strain showed stability in values that did not differ significantly ( $p>0.05$ ) during the collections at 12 and $24 \mathrm{~h}$ (see Table 2), demonstrating a homogenous distribution throughout the intestine, but in a lesser quantity when compared to the other Lactobacillus strains.

In all the strains, the bacterial counts observed in the duodenum at 12 and $24 \mathrm{~h}$ were similar of the negative control, demonstrating low adherence of the Lactobacillus evaluated in this segment.

The results obtained with the sequencing alignment showed a highly conserved region between nucleotides 369-391 corroborating with Dubernet et al. (2002). The strains 206, 231, 258, 262, 311 and 316 showed an identity 
Table 2 - Median count of bacteria adhering to intestinal epithelium, by in vivo assay, considering the strain, time after inoculation and intestinal segment.

\begin{tabular}{|c|c|c|c|c|c|}
\hline \multirow[t]{2}{*}{ Strain } & \multirow[t]{2}{*}{ Time (h) } & \multicolumn{4}{|c|}{ Intestinal Segment } \\
\hline & & Duodenum & Jejunum & Ileum & Cecum \\
\hline \multirow[t]{4}{*}{ Control -B. subtillis } & 1 & $12.2^{\mathrm{ab} \mathrm{x}_{*}}$ & $3.8^{\mathrm{bx}}$ & $49.6^{\mathrm{ax}}$ & $1.3^{\mathrm{bx}}$ \\
\hline & 4 & $0.7^{\mathrm{ax}}$ & $0.8^{\mathrm{ax}}$ & $0.4^{\mathrm{ax}}$ & $0.8^{\mathrm{ax}}$ \\
\hline & 12 & $0.8^{\mathrm{ax}}$ & $0.3^{\mathrm{ax}}$ & $0.0^{\text {a y }}$ & $0.5^{\mathrm{ax}}$ \\
\hline & 24 & $1.9^{\mathrm{ax}}$ & $1.0^{\mathrm{abx}}$ & $0.7^{\text {by }}$ & $0.5^{\mathrm{bx}}$ \\
\hline \multirow[t]{4}{*}{ Control + L. reuteri } & 1 & $215.5^{\mathrm{abx}}$ & $300.7^{\mathrm{ax}}$ & $301.9^{\mathrm{ax}}$ & $57.3^{\text {by }}$ \\
\hline & 4 & $22.9^{\text {by }}$ & $3.0^{\text {by }}$ & $5.2^{\text {by }}$ & $104.0^{\mathrm{ax}}$ \\
\hline & 12 & $6.4^{\text {by }}$ & $4.3^{\text {by }}$ & $3.4^{\text {by }}$ & $190.4^{\mathrm{ax}}$ \\
\hline & 24 & $3.8^{\text {ay }}$ & $10.2^{\text {ay }}$ & $2.8^{\text {ay }}$ & $9.9^{\text {az }}$ \\
\hline \multirow[t]{4}{*}{311} & 1 & $146.7^{\text {ax }}$ & $38.7^{\mathrm{ab} x}$ & $14.5^{\text {bc } x}$ & $2.1^{\mathrm{cx}}$ \\
\hline & 4 & $19.4^{\text {ay }}$ & $7.5^{\text {axy }}$ & $3.4^{\mathrm{ax}}$ & $4.3^{\mathrm{ax}}$ \\
\hline & 12 & $1.3^{\text {ay }}$ & $1.4^{\text {ab y }}$ & $1.4^{\mathrm{ab} x}$ & $10.1^{\mathrm{bx}}$ \\
\hline & 24 & $1.4^{\mathrm{ab} y}$ & $1.4^{\mathrm{aby}}$ & $0.7^{\mathrm{bx}}$ & $2.6^{\mathrm{ax}}$ \\
\hline \multirow[t]{4}{*}{262} & 1 & $251^{\mathrm{ax}}$ & $328.4^{\mathrm{ax}}$ & $192.2^{\mathrm{ax}}$ & $14.1^{\mathrm{bz}}$ \\
\hline & 4 & $21.3^{\text {by }}$ & $105.3^{\text {by }}$ & $125.4^{\mathrm{abx}}$ & $534.0^{\mathrm{ax}}$ \\
\hline & 12 & $1.4^{\mathrm{bz}}$ & $1.5^{\mathrm{bz}}$ & $1.2^{\mathrm{by}}$ & $155.5^{\text {ay }}$ \\
\hline & 24 & $0.5^{\mathrm{bz}}$ & $0.8^{\mathrm{bz}}$ & $0.6^{\text {by }}$ & $59.3^{\text {a yz }}$ \\
\hline \multirow[t]{4}{*}{258} & 1 & $163.0^{\text {a } y}$ & $102.9^{\text {a y }}$ & $67.4^{\mathrm{ax}}$ & $0.7^{\text {by }}$ \\
\hline & 4 & $63.6^{\text {ay }}$ & $8.9^{\mathrm{ax}}$ & $5.8^{\text {ay }}$ & $55.8^{\mathrm{ax}}$ \\
\hline & 12 & $0.5^{\mathrm{ax}}$ & $0.7^{\mathrm{ax}}$ & $0.4^{\text {ay }}$ & $5.7^{\text {ay }}$ \\
\hline & 24 & $0.9^{a x}$ & $0.1^{\mathrm{ax}}$ & $0.1^{\text {a }}$ & $1.7^{\text {a y }}$ \\
\hline \multirow[t]{4}{*}{231} & 1 & $17.2^{\mathrm{abx}}$ & $25.5^{\mathrm{ab} x}$ & $42.7^{\mathrm{ax}}$ & $0.0^{\text {by }}$ \\
\hline & 4 & $65.2^{a b y}$ & $192.2^{\text {ay }}$ & $18.0^{\mathrm{bxy}}$ & $150.8^{a b x}$ \\
\hline & 12 & $18.4^{\mathrm{abx}}$ & $16.6^{\mathrm{abx}}$ & $7.7^{\text {by }}$ & $53.2^{\mathrm{ax}}$ \\
\hline & 24 & $24.0^{a b x}$ & $12.6^{\mathrm{abx}}$ & $5.6^{\text {by }}$ & $71.4^{\mathrm{ax}}$ \\
\hline \multirow[t]{4}{*}{206} & 1 & $155.3^{\text {ay }}$ & $368.7^{\text {az }}$ & $172.6^{\mathrm{ax}}$ & $0.2^{\mathrm{bz}}$ \\
\hline & 4 & $85.5^{\text {ay }}$ & $46.8^{\text {axy }}$ & $33.8^{\text {ay }}$ & $125.8^{\mathrm{axy}}$ \\
\hline & 12 & $22.9^{\mathrm{bx}}$ & $67.0^{\text {ab y }}$ & $34.2^{\text {by }}$ & $252.9^{\mathrm{ax}}$ \\
\hline & 24 & $18.8^{\mathrm{ax}}$ & $9.1^{\mathrm{ab} x}$ & $1.4^{\mathrm{bz}}$ & $33.9^{\text {a } y}$ \\
\hline
\end{tabular}

* a,b,c Two medians followed by at least one different superscript, in the same row, do differ significantly ( $\mathrm{p} \geq 0.05)$, comparing the same strain and same time in different intestinal segments (Line).

${ }_{x, y, z}$ Two medians followed by at least one different superscript, in the same columm, do differ significantly ( $\left.\mathrm{p} \geq 0.05\right)$, comparing different times in the same strain and same intestinal segment (Column). 



Figure 4 - cFDA-staining Lactobacillus adhered to intestinal epithelium observed by fluorescent microscope (magnification 40). A- duodenum one hour after strain 258 inoculation; B - jejunum one hour after strain 231 inoculation; C - ileum four hours after positive control Lactobacillus reuteri inoculation D- cecum four hours after strain 206 inoculation.

of $100 \%$ with up to eight sequences of L. reuteri (CP002844.1; AP007281.1; CP000705.1; EU547293.1, EU547292.1, EU547290.1, EF412989.1; EF412988.1), allowing us to conclude that all strains analyzed belong to this specie.

\section{Discussion}

The difference found between the PCR and biochemical analyses corroborates De Martinis (2002), who considers the utilization of a fermentation pattern of carbohydrates unsatisfactory as a single criterion for identifying lactic acid bacteria, since frequent variations occur in the fermentations, enabling subjectivity in their interpretations.

Adhesion to intestinal mucosa can confer an important competitive advantage for bacterial maintenance in the gastrointestinal tract and it is generally accepted that adhesive properties contribute to the efficacy of probiotic strains (Servin and Coconnier, 2003).

Bouzaine et al. in 2005, utilizing the same methodology employed in the present study for the evaluation of in vitro adhesion, reported respective mean counts for the strains Lactobacillus rhamnosus TB1 and Lactobacillus reuteri LRT1 greater than 2000 and 500 cels per field, while those of the strains Lactobacillus johnsonii LJT2 and Lactobacillus salivarius LST1 were less than 250 cells per field. But Horie et al. in 2002 evaluated the adhesion capacity in BMM of Lactobacillus crispatus JCM 5810 and found an average of 70 bacterial cells per microscopic field.

The counts reported in previous studies are higher than most of the values observed in our study (except for the strains selected for the in vivo adhesion test), which may be explained by the fact that the physical-chemical nature of the external membrane of the cell wall, the conformation of macromolecules of the bacterial surface and the susceptibility to external factors (time, medium and general culture conditions) determine the propensity of Lactobacillus to adhere to a surface, factors that vary even within the same specie (Schar-Zammaretti and Ubbinik, 2003).

The CFDA SE cell tracer, utilized in the in vivo assay, is a compound capable of staining cells without compromising their viability or altering their adhesive characteristics, although during bacterial growth, when the bacterial concentration is expected to rise, the number of cells stained can decrease due to dilution of intracellular CFDA SE after cellular division (Fuller et al., 2000). Thus, to avoid discrepant results between the quantities of adhering bacteria vs. the number effectively stained, the present 
study opted to evaluate adhesion for a maximum period of $24 \mathrm{~h}$ after bacterial inoculation in the birds.

Lee et al. (2004) in an investigational study of the growth and colonization of Lactobacillus casei shirota stained by CFDA SE in rat intestines; determined that the Lactobacillus strain utilized presented in the first collection, at $24 \mathrm{~h}$, greater adhesion to the jejunum, in contrast to the data found in the present study, in which the strains, except for 258 , presented greater adhesion to ceca at $24 \mathrm{~h}$ after inoculation of birds.

According to Bouzaine et al. (2005) Lactobacillus rhamnosus $T B 1$ presented a low bacterial count in intestinal epithelium of birds, despite having demonstrated greater affinity for adhesion in the rectum, ileum and jejunum. The cecum was the segment that presented the least adhesion by Lactobacillus rhamnosus TB1, in agreement with the results of Edelman et al. (2002), who also observed low adhesion of different Lactobacillus species in the cecal epithelium of birds.

In our present work it was possible to identify a tendency among the strains evaluated to colonize the ceca, with less capacity to establish themselves in the duodenum or jejunum, especially in the $24 \mathrm{~h}$ period after inoculation, corroborating the results of Fuller and Turvey (1971) who reported a massive bacterial colonization of the ceca.

We verified that a single strain (258) presented homogeneity in intestinal colonization but also the lowest counts in the four intestinal segments evaluated at $24 \mathrm{~h}$ after inoculation. In contrast, strain 231 presented the highest adhesion values at $24 \mathrm{~h}$, but showed variations in its adhesive capacity in the different intestinal segments, at the moments analyzed.

These data confirm the strain-dependent nature of the intestinal adhesion capacity, since they may have differences in the structural conformation and composition of the bacterial cell wall, with these characteristics varying within the same genus and even within the same species of Lactobacillus (Servin and Coconnier, 2003; Deepika and Charalampopoulos, 2010).

Strain 231 also presented better adherence in the in vitro test utilizing BMM, and satisfactory results in the in vivo adhesion tests, significantly superior to the other ones and especially to the positive control (Table 2), demonstrating the relevance and correspondence of the in vitro with the in vivo results and suggesting that the in vitro technique employed may be utilized for the selection of possible probiotic strains.

Early studies on chicken microbiota found that Lactobacillus salivarius, L. reuteri, and L. acidophilus inhabited the crop and the chicken digestive tract. Our results show that the five strains sequenced are compatible with Lactobacillus reuteri specie, and agrees with the fact that this is the most abundant Lactobacillus species in the chicken gastrointestinal tract (Abbas Hilmi et al., 2007).
From the results obtained in the present study it can be concluded that the PCR technique is an important tool for identifying Lactobacillus spp., and can be utilized to validate the result of biochemical identification tests.

It may also be concluded that the in vitro adhesion process of Lactobacillus, utilizing the Basement Membrane Matrix (BMM) permits the selection of probiotic strains with adhesion capacity; also, the staining of Lactobacillus by CFDA SE is shown to be suitable for the visualization and counting of this bacterium adhering to the intestinal epithelium of birds, with both techniques being efficient for evaluating the adherence capacity of probiotic strains.

\section{Acknowledgments}

The authors thank the Sao Paulo State Research Support Foundation- FAPESP for funding the project.

\section{References}

Abbas Hilmi H, Surakka A, Apajalahti J, Saris PEJ (2007) Identification of the Most Abundant Lactobacillus Species in the Crop of 1- and 5-Week-Old Broiler Chickens. Appl Environ Microbiol 73:7867-7873.

Barros MR, Andreatti Filho RL, Oliveira DE, Lima ET, Crocci AJ (2009) Comparison between biochemical and polymerase chain reaction methods for the identification of Lactobacillus spp. isolated from chickens. Arq Bras Med Vet Zoot 61:319-325.

Bianchi MA, Del Rio D, Pellegrini N, Sansebastiano G, Neviani E, Brighenti F (2004) A fluorescence-based method for the detection of adhesive properties of lactic acid bacteria to Caco-2 cells. Lett App Microbiol 39:301-305.

Bouzaine T, Dauphin RD, Thonart P, Urdaci MC, Hamdi M (2005) Adherence and colonization properties of Lactobacillus rhamnosus TB1, a broiler chicken isolate. Lett App Microbiol 40:391-396.

Collado MC, Gueimonde M, Hernadez M, Sanz Y, Salminen S (2005) Adhesion of selected Bifidobacterium strains to human intestinal mucus and the role of adhesion in enteropathogen exclusion. J Food Protec 68:2672-2678.

Deepika G, Charalampopoulos D (2010) Surface and Adhesion Properties of Lactobacilli. Adv App Microbiol 70:127-152.

De Martinis ECP (2002). Identification of meat isolated bacteriocin-producing lactic acid bacteria using biotyping and ribotyping. Arq Bras Med Vet Zoot 54:659-661.

Dubernet S, Desmasures N, Guéguen M (2002) A PCR-based method for identication of lactobacilli at the genus level. FEMS Microbiol Lett 214:271-275.

Edelman S, Westerlund-Wikstrom B, Leskelas S, Kettunen H, Rautonen N, Apajalahti J, Korhonen TK (2002) In vitro adhesion specificity of indigenous Lactobacilli within the avian intestinal tract. Appl Environ Microbiol 68:51555159.

FAO/WHO (2002) Guidelines for the Evaluation of Probiotics in Food. Working Group Report.

Fuller ME, Turvey A (1971) Bacteria associated with the intestinal wall of the fowl (Gallus domesticus). J Appl Bacteriol $34: 617-22$. 
Fuller ME, Streger SH, Rothmel RK, Mailloux BJ, Hall JA, Onstott CT, Fredrickson KJ, Balkwill LD (2000) Development of vital fluorescent staining method for monitoring bacterial transport in subsurface environments. Appl Environ Microbiol 66:4486-4496.

Horie M, Ishiyama A, Fujihira-Ueki Y, Sillanpaa J, Korhonen TK, Toba T (2002) Inhibition of the adherence of Escherichia coli strains to basement membrane by Lactobacillus crispatus expressingan S-layer. Appl Environ Microbiol 92:396-403.

Huang MK, Choi YJ, Houde R, Lee JW, Lee B, Zhao X (2004) Effects of Lactobacilli and an Acidophilic Fungus on the Production Performance and Immune Responses in Broiler Chickens. Poul Sci 83:788-795.

Lee YK, Ho PS, Low CS, Arvilommi H, Salminen S (2004) Permanent colonization by Lactobacillus casei is hindered by the low rate of cell division in mouse gut. App Environ Microbiol 70:670-674.

Moreira JLS, Motta RM, Horta MF, Teixeira SMR, Neumann E, Nicoli JR, Nunes AC (2005) Identification to the species level of Lactobacillus isolated in probiotic prospecting studies of human, animal or food origin by $16 \mathrm{~S}-23 \mathrm{~S}$ rRNA restriction profiling. BMC Microbiol 5:15-19.

Morelli, L (2000) In vitro selection of probiotic lactobacilli: a critical appraisal. Curr Issues Intest Microbiol 1:59-67.
Munoz-Provencio D, Llopis M, Antolin M, Torres I, Guarner F, Pérez-Martinex G, Monedero V (2009) Adhesion properties of Lactobacillus casei strains to resected intestinal fragments and components of the extracellular matrix. Arch Microbiol 191:153-161.

Sampaio, IBM (2002) Estatística Aplicada à Experimentação Animal. Editora FEPMVZ, Belo Horizonte.

Schar-Zammaretti P, Ubbinik J (2003) The cell wall of lactic acid bacteria: Surface constituents and macromolecular conformations. Bioph J 85:4076-4092.

Servin AL, Coconnier MH (2003) Adhesion of probiotic strains to the intestinal mucosa and interaction with pathogens. Best Pract Res Clin Gastroenterol 17:741-754.

Surhone LM, Timpledon MT, Marseken SF (2010) Probiotics. VDM Verlag AG \& Co. Kg, p. 164.

Tamura K, Peterson D, Peterson N, Stecher G, Nei M, Kumar S (2011) MEGA5: Molecular Evolutionary Genetics Analysis using Maximum Likelihood, Evolutionary Distance, and Maximum Parsimony Methods. Molecular Biology and Evolution.

Velez M P, De Keersmaecker SCJ, Vanderleyeden J (2007) Adherence factors of Lactobacillus in the human gastrointestinal tract. FEMS Microbiol Lett 276:140-148.

Zar JH (2009) Bioestatistical Analysis. Pearson, Prentice Hall, Upper Saddle River, p. 960.

All the content of the journal, except where otherwise noted, is licensed under a Creative Commons License CC BY-NC. 